\title{
COLANGITE CRÔNICA ASSOCIADA À INFESTAÇÃO DE TREMATÓDEO POR PLATYNOSOMUM FASTOSUM, CONCOMITANTE À VESÍCULA BILIAR DUPLA EM UM GATO - RELATO DE CASO.
}

\author{
Karina Maria Basso ${ }^{1}$ \\ Alexandre Arenales ${ }^{2}$ \\ Nazilton de Paula Reis Filho ${ }^{3}$ \\ Mauro José Lahm Cardoso ${ }^{4}$ \\ Celmira Calderón ${ }^{4}$
}

\begin{abstract}
RESUMO
Este trabalho tem o objetivo de relatar um caso de um felino de cinco anos, sem raça definida, apresentando icterícia intensa, petéquias e equimoses cutâneas generalizadas, aumento da enzima ALT, aumento de colesterol sérico e diminuição de proteínas plasmáticas. Foi instituído tratamento médico, entretanto o animal morreu dois dias após a intervenção clínica. No exame anatomopatológico observou-se colangite crônica associada à infestação de trematódeo Platynosomum fastosum e vesícula biliar dupla verdadeira. Conclui-se que alterações anatômicas associadas à infestação por parasitas podem agravar significativamente o quadro clínico de colangite crônica e devem sempre ser consideradas no plano diagnóstico.
\end{abstract}

Palavras-chave: Anomalias congênitas da vesícula biliar, trematódeo hepático, colangite crônica.

\section{CHRONIC CHOLANGITIS ASSOCIATED WITH LIVER FLUKE INFESTATION CAUSED BY PLATYNOSOMUM FASTOSUM, CONCURRENT WITH GALLBLADDER DUPLICATION IN A DOMESTIC CAT - CASE REPORT.}

\begin{abstract}
This paper aims to report a case of a 5-years-old, mixed breed cat showing severe jaundice, skin petechiae and ecchymosis, high values of ALT enzyme and serum cholesterol and low plasmatic proteins. A medical treatment was instituted; however the animal died two days after clinical intervention. Anatomicopathological analisys showed a chronic cholangitis associated with liver fluke infestation caused by Platynosomum fastosum, and duplex gallbladder. We conclude that anatomical changes associated with infestation by parasites may significantly aggravate the clinical condition of chronic cholangitis and should always be considered in the diagnostic plan.
\end{abstract}

Key words: gallbladder congenital anomalies, hepatic fluke, chronic cholangitis.

\section{COLANGITIS CRÓNICA ASOCIADA A LA INFESTACIÓN POR TREMATODO HEPÁTICO CAUSADO POR PLATYNOSOMUM FASTOSUM, CONCURRENTE CON LA DUPLICACIÓN DE LA VESÍCULA BILIAR EN EL GATO DOMÉSTICO - PRESENTACIÓN DE UN CASO.}

\footnotetext{
${ }^{1}$ Doutoranda no Departamento de Medicina Veterinária Preventiva, Universidade Estadual de Londrina. Contato principal para correspondência.

2 Anatomopatologista Veterinário autônomo

${ }^{3}$ Mestrando na Universidade Estadual Paulista - Unesp campus de Jaboticabal

${ }^{4}$ Docente na Universidade Estadual do Norte do Paraná - UENP campus de Bandeirantes
}

Bass KM, Arenales A, Reis Filho NP, Cardoso MJL, Calderón C. Colangite crônica associada à infestação de trematódeo por Platynosomum fastosum, concomitante à vesícula biliar dupla em um gato - Relato de caso. Vet. e Zootec. 2018 mar.; 25(1): 079-084. 


\section{RESUMEN}

Este trabajo pretende informar un caso de un felino de cinco años mestizo, presentando intensa ictericia, petequias y equimosis cutánea generalizada, aumento de enzima ALT, aumento del colesterol sérico y disminución de las proteínas plasmáticas. Se instituyó el tratamiento médico, pero el animal murió dos días después de la intervención clínica. El examen histopatológico mostró colangitis crónica asociada con infestación por trematodos Platynosomum fastosum y verdadera duplicación de la vesícula biliar. Se conclui que los cambios anatómicos asociados con la infestación por parásitos pueden agravar significativamente el cuadro clínico de colangitis crónica y siempre debe ser considerado en el plan de diagnóstico.

Palabras Claves: anomalías congénitas de la vesícula biliar; trematodo hepático; colangitis crónica.

\section{INTRODUÇÃO}

$\mathrm{Na}$ medicina de felinos, as colangites se encontram entre as principais afecções clínicas, em especial pela susceptibilidade anatômica, onde há maior facilidade da ascensão de bactérias do intestino para trato biliar (1,2). Em 2006 a Word Small Animal Veterinary Association (WSAVA) propôs uma padronização na nomenclatura das doenças biliares sendo as colangites de felinos divididas em quatro grupos: colangite neutrofílica, colangite linfocítica, colangite destrutiva e a colangite crônica associada à infestação de trematódeos (3).

Dentre os quadros de colangite crônica associada à infestação de trematódeos, o Platynosomum fastosum é o parasita trematódeo mais comum de fígado de gatos domésticos no Brasil. Este se encontra comumente nos ductos biliares e vesícula biliar, e é capaz de causar um quadro de hepatopatia $(2,4,5)$. O Platynosomum fastosum é comum nas regiões tropicas e subtropicais por todo o mundo (6); No Brasil, a prevalência do parasita varia conforme a localização do animal, alcançando de 1,91 a $45 \%$ (7).

$\mathrm{Na}$ maioria das vezes a infestação por $P$. fastosum é assintomática ou causa poucos sinais clínicos, entretanto deve-se considerar a carga parasitária, o tempo de parasitismo e a reação individual do hospedeiro. Portanto, nas infestações graves e crônicas é possível ocorrer obstrução dos canalículos biliares e consequente sobrecarga hepática, resultando em cirrose biliar $(2,4,5,8)$. Microscopicamente, o fígado infestado por $P$. fastosum apresenta ectasia dos ductos biliares, e no lúmen pode-se visualizar o parasita trematódeo, caracterizado por cutícula fina, cavidade sólida, testículo, ovário e ovos operculados. Conforme aumenta a carga parasitária, a presença mecânica do parasita intraductal leva a uma obstrução de ductos biliares e colestase intra-hepática, associada à fibrose e inflamação linfocítica predominantemente portal, bem como, hiperplasia ductal. O parênquima também poderá ser afetado, em que se verifica perda da arquitetura dos cordões de hepatócitos associada a presença de colônias bacterianas e infiltrado neutrofílico. Ocasionalmente ocorre hiperplasia papilar do epitélio dos ductos; proliferação cística do epitélio ductal com preenchimento luminal por conteúdo mucinoso e a visualização de ovos operculados livres no lúmen ductal $(1,9)$.

Outro fator que deve ser considerado é que geralmente essas infecções biliares ascendentes necessitam de algum fator predisponente como a estase biliar, colelitíase ou anormalidades anatômicas (10). A vesícula biliar dupla é uma alteração congênita, raramente observada em humanos $(6,11,12)$, quase não descrita na medicina veterinária e leva à sobrecarga biliar com lesão hepática $(13,14)$.

Bass KM, Arenales A, Reis Filho NP, Cardoso MJL, Calderón C. Colangite crônica associada à infestação de trematódeo por Platynosomum fastosum, concomitante à vesícula biliar dupla em um gato - Relato de caso. Vet. e Zootec. 2018 mar.; 25(1): 079-084. 
Qualquer das quatro formas de apresentação da colangite nos felinos não revela características particulares no exame físico ou anamnese, em geral os sinais são sistêmicos e inespecíficos como: êmese, anorexia, depressão, distensão abdominal, perda de peso, febre, diarréia, desidratação e icterícia $(2,7,15)$. Portanto, o diagnóstico diferencial é importante para diferenciar qual é a forma da colangite, e este deve ser feito associado os exames auxiliares de ultrassonografia abdominal, biópsia hepática, citopatologia e cultivo da bile, para pesquisa de ovos e bactérias (5).

O presente relato se justifica pela ausência de descrições na literatura que citem a ocorrência simultânea de doenças do trato biliar em felinos, a duplicação verdadeira da vesícula biliar e infecção hepática por P. fastosum.

\section{RELATO DE CASO}

Um felino de cinco anos, sem raça definida, fêmea foi encaminhado ao atendimento clínico veterinário. O animal pesava $3,2 \mathrm{~kg}$ e apresentava histórico de emagrecimento progressivo, êmese, diarreia, anorexia, adipsia, protocolo antiparasitário atrasado e livre acesso à rua na cidade de Bandeirantes, na região do norte do Paraná. Ao exame físico demonstrou aumento da sensibilidade abdominal, icterícia intensa, petéquias e equimoses cutâneas generalizadas.

Os exames complementares solicitados revelaram aumento moderado da enzima aspartato aminotransferase (ALT) (534 UI/L), aumento de colesterol $(211 \mathrm{mg} / \mathrm{dl})$, aumento da proteína total $(8,8 \mathrm{~g} / \mathrm{dl})$, e diminuição de albumina $(1,96 \mathrm{~g} / \mathrm{dl})$. O hemograma revelou leucocitose com neutrofilia e desvio a esquerda, além de discreta trombocitopenia. A urinálise evidenciou bilirrubinúria e proteinúria. Em ultrassonografia abdominal observou-se aumento da ecogeinicidade em região epigástrica.

Foi instituído o tratamento com fluidoterapia com solução fisiológica com glicose 5\%, acrescida de vitaminas do complexo B e C, além do uso de hepatoprotetor (Ornitil ${ }^{\circledR}$ ), porém o animal morreu dois dias após o atendimento.

Ao exame necroscópico, se observou a duplicação verdadeira da vesícula biliar (Figura 1), e o fígado com consistência firme, padrão lobular evidente distribuído de maneira difusa. Macroscopicamente não se observou a presença de parasitas ou espessamento dos ductos biliares, entretanto o ducto biliar comum encontrava-se espessado e sem fluxo de bile para o duodeno (manobra de Virchow negativa).

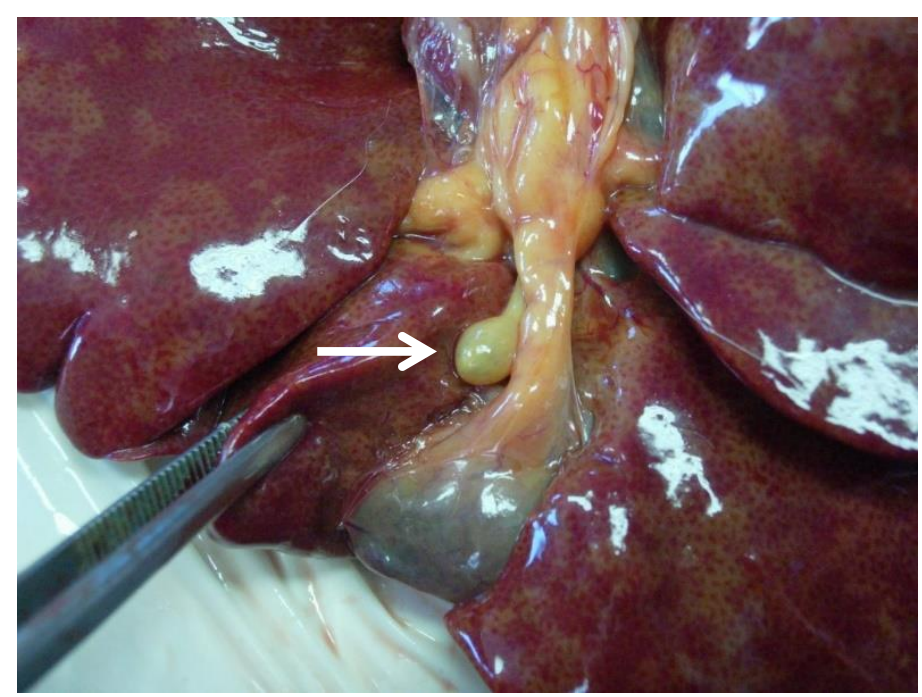

Figura 1. Fígado de felino que apresentou duplicação verdadeira da vesícula biliar (seta) e parênquima hepático com padrão lobular evidente e áreas multifocais a coalescentes, amareladas.

Bass KM, Arenales A, Reis Filho NP, Cardoso MJL, Calderón C. Colangite crônica associada à infestação de trematódeo por Platynosomum fastosum, concomitante à vesícula biliar dupla em um gato - Relato de caso. Vet. e Zootec. 2018 mar.; 25(1): 079-084. 
Microscopicamente, no fígado observaram-se ductos biliares hiperplásicos associados a intensa ectasia. Região portal com fibrose moderada associada a infiltrado linfoplasmocitário moderado (Figura 2) e no conteúdo biliar intraductal foram observados ovos operculados e de casca espessa, compatíveis com ovos de P. Fastosum (Figura 3). O parênquima adjacente apresentou, de forma difusa degeneração vacuolar de hepatócitos associada a moderada desorganização das trabéculas de hepatócitos.

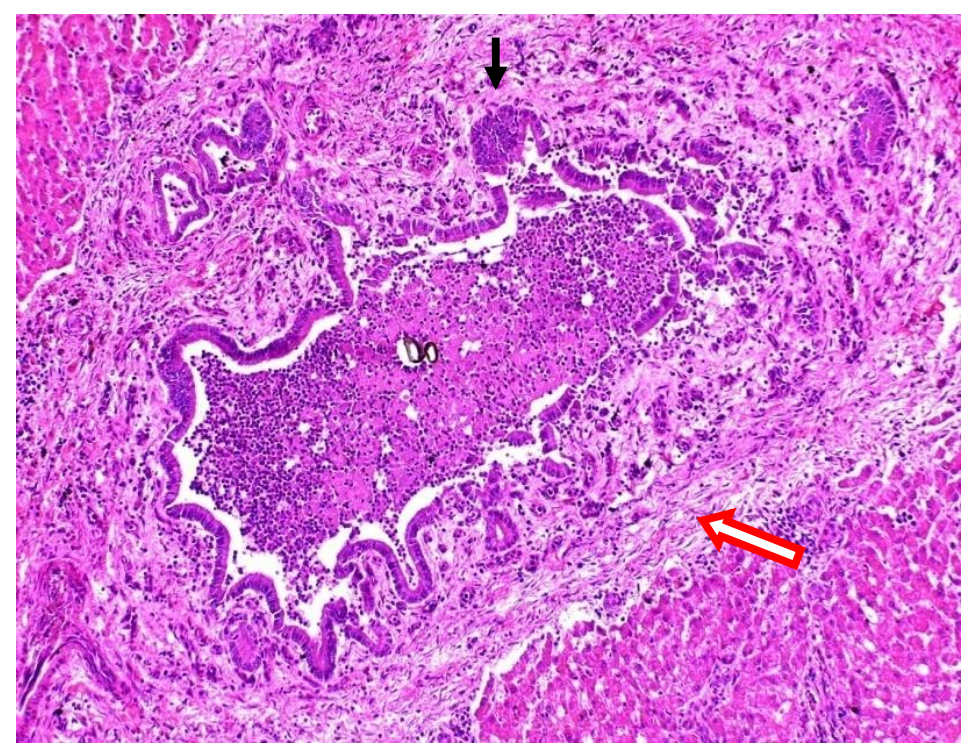

Figura 2. Fotomicrografia de fígado felino. Notar hiperplasia de células epiteliais do ducto biliar (seta preta), associado à fibrose periportal (seta vermelha). Hematoxilina e Eosina, Obj. de 10x.

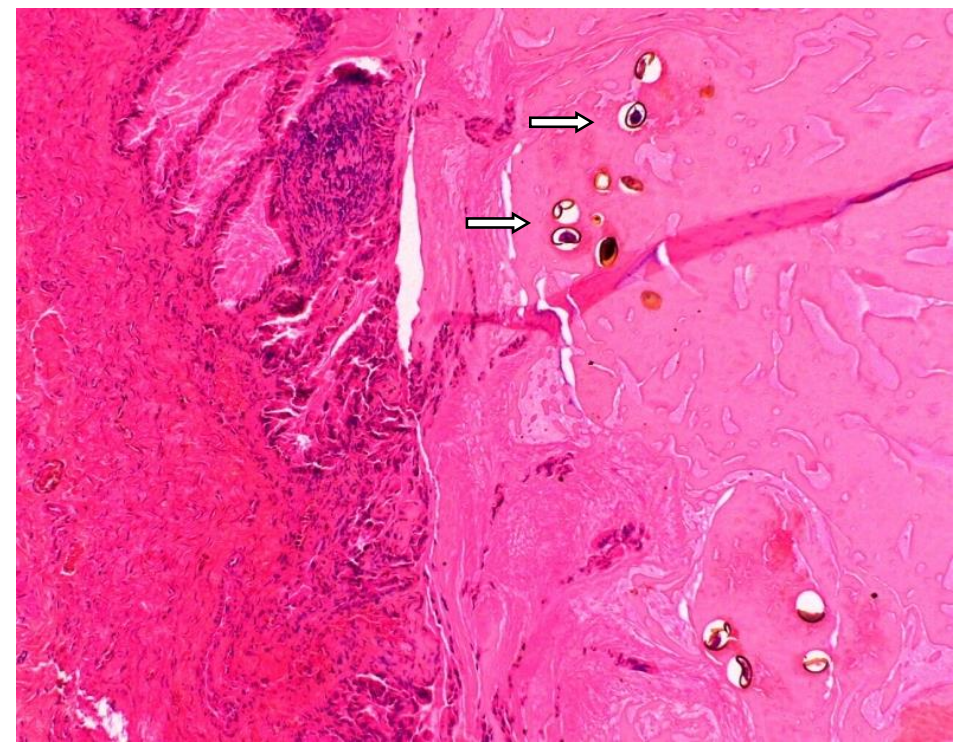

Figura 3. Vesícula biliar de felino. Notar a presença de ovos operculados (setas) de Platynosomum fastosum mesclados ao conteúdo da vesícula biliar. Hematoxilina e Eosina, Obj. de 10x.

\section{DISCUSSÃO}

No presente relato de caso, os achados histopatológicos permitiram concluir um quadro de platinossomíase, devido à visualização de ovos operculados, fibrose e colangite linfocítica Bass KM, Arenales A, Reis Filho NP, Cardoso MJL, Calderón C. Colangite crônica associada à infestação de trematódeo por Platynosomum fastosum, concomitante à vesícula biliar dupla em um gato - Relato de caso. Vet. e Zootec. 2018 mar.; 25(1): 079-084. 
que envolvia a região portal e extendia-se para o parênquima. A ausência de parasitas trematódeos na análise macro e microscópica do fígado, coincide com os relatos de Headley (1), que destacou que apesar de atípica, a visualização de ovos operculados é uma característica diagnóstica do P. fastosum.

De acordo com a classificação da WSAVA (3), o presente caso caracteriza-se por uma colangite crônica associada à infestação de trematódeos, entretanto $P$. fastosum não é citado nessa classificação. Assim ao avaliar o presente caso e outros relatos e estudos, sua importância é indiscutível em casos de hepatopatias de felinos no Brasil.

Embora ocorra inespecificidade dos sinais sistêmicos para a colangite crônica, a disfunção hepática devido ao processo inflamatório que envolvia todo o parênquima, resultou em icterícia, petéquias e equimoses, que também foram observadas por outros autores (7) e Brain $(10,11)$. Esta inespecificidade faz dos exames auxiliares, principalmente a biópsia hepática, pontos críticos para a elucidação do diagnóstico e uma consequente terapia adequada, assim como recomendado pela WSAVA (3).

Apesar do tratamento dos casos crônicos ou de cirrose biliar ser limitado quanto à cura, pode-se obter melhores resultados no tratamento ou aumento na sobrevida do animal com o diagnóstico preciso e precoce.

O presente relato de caso coincide com os autores Brain (11); Stanley (15) e Pressel (6), os quais afirmaram que alterações anatômicas, como a duplicação da vesícula biliar, com sobrecarga da bile e/ou a presença de parasitas nos ductos biliares, predispõem o desenvolvimento de colangites, obstrução ductal e fibrose periportal. Carreira (8) destacou que a infestação por $P$. fastosum promove a estase biliar e pode favorecer a contaminação ascendente do trato biliar e consequentemente levar ao envolvimento hepático e agravamento do quadro. Esses aspectos estão de acordo com os relatados no presente estudo.

\section{CONCLUSÕES}

As doenças do trato biliar em felinos, principalmente a colangite crônica por infestação parasitária, são raramente descritas na literatura, mas são de grande importância no atendimento clínico desta espécie, devido à gravidade do quadro no momento do diagnóstico. Portanto, a colangite crônica associada à infestação de trematódeos (Platynosomum fastosum) deve ser considerada no diagnóstico diferencial dos processos patológicos que envolvem a vesícula biliar e ductos em felinos.

A associação da anomalia congênita de vesícula biliar dupla com a infestação parasitária nos ductos e vesícula biliar intensifica o processo inflamatório hepático, dificulta o tratamento e pode, assim como presente relato, culminar no óbito do animal.

\section{REFERÊNCIAS}

1. HEADLEY SA, FERIOLI RB, REIS ACF, BRACARENSE APFRL. Platynosomum fastosum-induced Infections in Domestic Shorthair Cats: a Retrospective Study of Seven Cases. Brazilian Journal of Veterinary Pathology. 2011;4(3):227-234.

2. SAMPAIO MAS, BERLIM CM, ANGELIM AJGL et al, Infecção natural pelo Platynosomum Looss 1907, em gato no município de Salvador, Bahia. Revista Brasileira de Saúde e Produção Animal. 2006;7:01-06.

3. Van den Ingh, TSGAM, CULLEN JM, TWEDT DC, WINKLE TV, DESMET VJ, ROTHUIZEN J. Morphological classification of biliary disorders of the canine and feline liver. In: Word Small Animal Veterinary Association (WSAVA) Liver Standardization

Bass KM, Arenales A, Reis Filho NP, Cardoso MJL, Calderón C. Colangite crônica associada à infestação de trematódeo por Platynosomum fastosum, concomitante à vesícula biliar dupla em um gato - Relato de caso. Vet. e Zootec. 2018 mar.; 25(1): 079-084. 
Group. Standards for Clinical and Histological Diagnosis of Canine and Feline Liver Diseases. Spain:Elsevier, 2006. p.61-76.

4. DANIEL AGT, DIAZ RF, CAMMIGNATTO LO, KAGE NK, PELLEGRINO A, COGLIATI B. Policystic liver disease associated with Platynossomum fastosum infection in a cat. Brazilian Journal of Veterinary Pathology. 2012;5(3):137-141.

5. CASTRO LS, ALBUQUERQUE GR. Ocorrência de Platynosomum iliciens em felinos selvagens mantidos em cativeiro no estado da Bahia, Brasil. Rev. Bras. Paras. Vet. 2008;17:239-241.

6. PRESSEL MA, FOX LE, APLEY MD, SIMUTIS FJ. Vancomycin for multi-drug resistant Enterococcus faecium cholangiohepatitis in a cat. Journal of feline medicine and surgery. 2005;7:317-321.

7. SALOMÃO M, SOUZA-DANTAS LM, BRANCO AS, BASTOS OPM, STERMAN F, LABARTHE N. Ultrasonography in hepatobiliary evaluation of domestic cats (felis catus, 1., 1758) infected by platynosomum looss, 1907. The Journal of Applied Research in Veterinary Medicine. 2005;3(1):271-279.

8. CARREIRA VS, VIEIRA RFC, MACHADO GF, LUVIZOTTO MCR. Feline cholangitis/cholangiohepatitis complex secondary to platynosomum fastosum infection in a cat. Revista Brasileira de Parasitologia Veterinária. 2008;17:184-187.

9. VIEIRA ALS, ECCO R, LIMA WS, GUEDES RMC. Platynossomum fastosum infection in two cats in Belo Horizonte, Minas Gerais State - Brazil. Brazilian Journal of Veterinary Pathology. 2009;2(1):45-48.

10. ILHA MR, et al. Cirrose biliar em felinos associada a ectasia do ducto cístico. Ciência Rural. 2004;34:1147-1153.

11. BRAIN PH, BARRS VR, MARTIN P, et al. Feline cholecystitis and acute neutrofilic cholangitis; Clinical findings, bacterial isolates and response to tratament in six cases. J. Fel. Med. Sur. 2006;8:91-103.

12. COELHO JCU, et al. Colecistectomia Laparóscopica em um paciente com ducto cístico duplo. Rev. Col. Bras. Circ. 2003;30:486-488.

13. MOENTK J, BILLER DS. Bilobed gallbladder in a cat: ultra-sonographic appearance. Journal of Veterinary Radiology and Ultrasound. 1992;34:354-356.

14. MOORES AL, GREGORY SP. Duplex gall bladder associated with choledocholithiasis, cholecystitis, gall bladder rupture and septic peritonitis in a cat.Journal of Small Animal Practic. 2007;48:404-409.

15. STANLEY LM. Update on the Diagnosis and Management of Feline Cholangiohepatitis. In: FELINE MEDICINE SYMPOSIUM, 2003, USA. Anais...USA: School of Veterinary Medicine, 2003. 